\title{
Adaptation of the Membrane Fatty Acid Composition by Growth in the Presence of n-Alkanols Influences Glycosyltransferase Expression in Streptococcus salivarius
}

\author{
By LYNDA J. MARKEVICS, KIM K. KAH, LEANDER RATHSAM, \\ LAURENCE W. TURNER AND NICHOLAS A. JACQUES* \\ Institute of Dental Research, 2 Chalmers Street, Surry Hills, New South Wales 2010, Australia
}

(Received 7 August 1986; revised 7 January 1987)

\begin{abstract}
Growth of Streptococcus salivarius ATCC 25975 in the presence of n-alkanols in the series methanol to decan-l-ol led to a decrease in the unsaturated to saturated fatty acid ratio. Each member of the set of $n$-alkanols which was examined over a range of concentrations possessed a point at which extracellular glucosyltransferase (GTF) production was minimal; increasing the concentration of the n-alkanol past this point stimulated GTF production. This effect was greatest with hexan-1-ol although it was observed to a lesser extent with pentan-1-ol and heptan1-ol. Reduced cell-associated fructosyltransferase activity was observed with increasing concentrations of each n-alkanol. Growth in the presence of $25 \mathrm{mM}$-propan-1-ol gave rise to a fatty acid profile in which $55 \%$ of the fatty acids were of an odd chain length. $S$. salivarius ATCC 25975 was shown to be able to utilize ethanol in a similar manner to propan-1-ol by growing it in the presence of $400 \mathrm{~mm}-\left[{ }^{14} \mathrm{C}\right]$ ethanol. Analysis of the membrane lipids at the stationary phase of growth indicated that $17.6 \%$ of the carbon of the fatty acids was derived from ethanol. A leaky adh mutant, $S$. salivarius MJ 37501, was isolated. The leaky nature of the mutant enabled it to incorporate reduced levels of odd-chain-length fatty acids into its membrane lipids when grown in the presence of 100 mM-propan-1-ol, but not when grown in the presence of 25 mM-propan-1-ol. S. salivarius ATCC 25975 therefore metabolized propan-1-ol (and ethanol) via a constitutive alcohol dehydrogenase.
\end{abstract}

\section{INTRODUCTION}

The fatty acid composition of the Gram-negative organism Escherichia coli has been shown to alter in the presence of n-alkanols of different chain length (Ingram, 1976; Sullivan et al., 1979). It has been proposed that the changes in fatty acid composition are an adaptive response to the physico-chemical interactions of the $n$-alkanols with the plasma membrane and that the nalkanols exert their effect by perturbing the packing order of the lipids in the bilayer (Seeman, 1972). The resultant changes in fluidity are considered in many ways to be analogous to those induced by changes in temperature (Marr \& Ingraham, 1962; Ingram, 1982). In E. coli K12, growth in the presence of n-alkanols of $\mathrm{C}_{1}-\mathrm{C}_{4}$ chain length causes an increase in the unsaturated to saturated fatty acid $(\mathrm{U} / \mathrm{S})$ ratio, while n-alkanols of $\mathrm{C}_{5}-\mathrm{C}_{10}$ chain length cause the opposite change (Ingram, 1976). However, in the case of E. coli ML308, the addition of butan-1-ol causes a decrease in the U/S ratio (Sullivan et al., 1979). Strain differences and culture conditions notwithstanding, the increase in the $\mathrm{U} / \mathrm{S}$ ratio observed when $E$. coli $\mathrm{K} 12$ is grown in the presence of ethanol has been the subject of much conjecture, since by increasing the degree of unsaturation in $E$. coli membranes, ethanol would be expected to further increase fluidity rather than decrease it. The apparent paradox appears to have been resolved since the lipid-to-protein

\footnotetext{
Abbreviations: ADH, alcohol dehydrogenase; GTF, glucosyltransferase; FAME, fatty acid methyl esters; FTF, fructosyltransferase; U/S ratio, ratio of unsaturated to saturated fatty acids.
} 
ratio of the plasma membrane of $E$. coli decreases when cells are grown in the presence of ethanol, thus compensating for the fluidizing effect brought about by the increase in lipid unsaturation (Dombek \& Ingram, 1984).

By comparison with E. coli, studies of the effects of n-alkanols on Gram-positive organisms have been far less rigorous and have involved species in which unsaturated fatty acids are either minor constituents of or absent from the plasma membrane (Rigomier et al., 1980; Herrero et al., 1982). In Bacillus licheniformis, long-chain n-alkanols preferentially suppress normal extracellular enzyme formation (Fishman et al., 1980). Amphiphilic molecules which perturb the membrane of Streptococcus salivarius also alter the degree of expression of extracellular glucosyltransferases (GTF) as well as cell-associated fructosyltransferases (FTF) (Jacques, 1983, 1985). The stimulation of extracellular GTF production in oral streptococci either by non-ionic surfactants containing oleic acid residues (Umesaki et al., 1977; Shimamura et al., 1983; Jacques et al., 1985), or by variations in $\mathrm{K}^{+}$concentrations, which also influence membrane composition (Markevics \& Jacques, 1985), has implicated membrane lipids containing $\mathrm{C}_{18^{-}}$ unsaturated fatty acids in the secretion of the enzyme. It was therefore of interest to observe alterations in the membrane fatty acids of $S$. salivarius by growing the bacterium in the presence of a series of $n$-alkanols, especially as this bacterium contains primarily linear saturated and unsaturated fatty acids similar to $E$. coli. Alterations in the expression of GTF and FTF under these conditions were also determined.

\section{METHODS}

Chemicals. $\left[\mathrm{U}-{ }^{14} \mathrm{C}\right.$-glucosy! $] \mathrm{Sucrose},\left[\mathrm{U}-{ }^{14} \mathrm{C}\right.$-fructosyl]sucrose, $\left[1^{-14} \mathrm{C}\right]$ ethanol and the liquid scintillation cocktail Aquasol-2 were purchased from New England Nuclear. Prop-2-en-1-ol (allyl alcohol) was obtained from Merck, BSA, Tris and NAD from Sigma, and alumina from BDH. The muramidase enzyme preparation, $\mathrm{M}-1$, from Streptomyces globisporus 1829 was kindly supplied by K. Yokogawa, Dainippon Pharmaceutical Co., Osaka, Japan (Yokogawa et al., 1975). The n-alkanols were of the highest grade available; all other reagents were of analytical reagent grade.

Organisms and growth. S. salivarius ATCC 25975 and S. salivarius MJ 37501 (this study) were stored or grown to late-exponential or early-stationary phase in semi-defined medium (SDM) containing $1 \mathrm{~mm}-\mathrm{CaCl}_{2}$ (Jacques, 1983). Initial data collection for analysis of fatty acid composition and measurement of glycosyltransferase activities involved experiments with the various n-alkanols in the series methanol to decan-1-ol, in which $S$. salivarius ATCC 25975 was grown in $250 \mathrm{ml}$ Pyrex screw-top bottles containing $55 \mathrm{ml}$ medium. As samples of these cultures were aseptically removed and replaced at $15 \mathrm{~min}$ intervals in order to monitor growth, conditions were more aerobic than in $5.5 \mathrm{ml}$ or $11 \mathrm{ml}$ volume cultures grown in capped test tubes $(14 \mathrm{~mm}$ i.d.).

Isolation of prop-2-en-1-ol resistant mutants. Spontaneous mutants of $S$. salivarius ATCC 25975 resistant to prop2-en-1-ol (allyl alcohol) (Rando, 1974) were selected by plating cells on SDM agar containing 200 mM-prop-2-en-1ol. Individual colonies were isolated and cultured overnight in SDM containing $20 \mathrm{~mm}$-prop-2-en-1-ol. After replating and reisolating twice more, mutants were grown in SDM and assayed for alcohol dehydrogenase (ADH) activity. One of these mutants, designated MJ 37501, was used for further study.

Enzyme assays. Cell-associated and extracellular glycosyltransferase activities were assayed as previously described (Jacques, 1985).

In order to assay ADH activity, cells were grown in $110 \mathrm{ml}$ batches to mid-exponential phase, harvested by centrifugation $\left(10000 \mathrm{~g}, 4^{\circ} \mathrm{C}, 10 \mathrm{~min}\right)$, washed twice and resuspended to $2 \mathrm{ml}$ in $50 \mathrm{~mm}$-potassium phosphate buffer $\mathrm{pH} 6.5$. The resuspended cells were lysed by incubating them at $37^{\circ} \mathrm{C}$ for $1 \mathrm{~h}$ after the addition of $100 \mu \mathrm{l} \mathrm{M}-1$ enzyme in water $\left(10 \mathrm{mg} \mathrm{m}^{-1}\right)$. The crude supernatant fraction was obtained by centrifugation $\left(50000 \mathrm{~g}, 4^{\circ} \mathrm{C}\right.$, $15 \mathrm{~min}$ ). ADH activity in the soluble fraction was assayed spectrophotometrically at $37^{\circ} \mathrm{C}$ by following the production of NADH at $338 \mathrm{~nm}$ (Racker, 1955). The cuvette contained NAD $(1 \mu \mathrm{mol})$, ethanol or propan-1-ol $(20 \mu \mathrm{l})$, enzyme preparation $(100 \mu \mathrm{l})$ and $20 \mathrm{~mm}$-Tris/ $\mathrm{KH}_{2} \mathrm{PO}_{4}$ buffer $\mathrm{pH} 8.0$ to give a final volume of $1.0 \mathrm{ml}$. The amount of protein added to the assay mixture was determined by the method of Bradford (1976) using BSA as standard. One unit of ADH activity was defined as that capable of reducing $1 \mu \mathrm{mol} \mathrm{NAD} \min ^{-1}(\mathrm{mg} \text { protein) })^{-1}$.

Preparation and analysis of fatty acids. The membrane lipids were extracted and the fatty acid methyl esters (FAME) of the acyl lipids prepared and analysed as reported previously (Markevics \& Jacques, 1985). The crude FAME were dissolved in hexane and further purified on $8 \times 1 \mathrm{~cm}$ alumina columns packed in hexane. The purified FAME were eluted from the columns with $5 \%(\mathrm{v} / \mathrm{v})$ diethyl ether in hexane and evaporated to dryness under a stream of $\mathrm{N}_{2}$ at $<25^{\circ} \mathrm{C}$. By comparing the amount of radioactivity present in the purified FAME obtained from a $5 \mathrm{ml}$ culture grown in the presence of $400 \mathrm{~mm}-\left[{ }^{14} \mathrm{C}\right]$ ethanol $\left(19 \cdot 5 \mathrm{Ci} \mathrm{mol}^{-1} ; 722 \mathrm{GBq} \mathrm{mol}^{-1}\right)$ with the amount and composition of FAME obtained from a 1.5 litre culture grown in the presence of the same 
concentration of non-radioactive ethanol, the amount of carbon in the fatty acids of the membrane lipids derived from the added ethanol could be estimated.

Analysis of data. Data from individual experiments are reported unless otherwise indicated (see below). Where appropriate, results are presented as the mean and standard deviation ( $n=$ number of experiments).

\section{RESULTS}

Preliminary observations with $S$. salivarius grown in the presence of n-alkanols of different chain length

In batch cultures of $E$. coli $\mathrm{K} 12$, the toxic concentration of a given n-alkanol is related to its chain length. Furthermore, the higher the concentration of a given n-alkanol, the greater the degree of change in the pattern of the membrane fatty acids (Ingram, 1976; Sullivan et al., 1979). Experiments were therefore done with $5.5 \mathrm{ml}$ batch cultures of $S$. salivarius to determine what concentration of each n-alkanol would approximately double the generation time $\left(t_{\mathrm{d}}\right)$ observed in the absence of any added alkanol (data not shown). Applying this knowledge to $55 \mathrm{ml}$ batch cultures of $S$. salivarius gave rise to lesser and greater effects on the $t_{\mathrm{d}}$ than had been observed in the preliminary experiments (Table 1). Because of this problem and the fact that each n-alkanol was not examined over a range of concentrations, it could not be stated unequivocally that the toxic concentration of a given n-alkanol was related to its chain length as was the case for $E$. coli. However, the data were useful in directing attention towards certain n-alkanols and their effects on the physiology of $S$. salivarius. For instance, an increase in extracellular GTF activity appeared to be favoured by the addition of hexan-1-ol to the culture medium (Table 1). Second, cell-associated FTF activity appeared to be suppressed in all cultures to which an n-alkanol had been added (Table 1). Third, the $\mathrm{U} / \mathrm{S}$ ratio of the fatty acids of the membrane lipids decreased regardless of the chain length of the n-alkanol added to the culture medium (Table 2). Fourth, the odd-chain-length n-alkanols gave rise to odd-chain-length fatty acids; this was particularly apparent for cells grown in the presence of propan-1-ol, when odd-chain-length fatty acids represented $75 \%$ of the total fatty acid profile (Table 2 ).

After these preliminary investigations, all subsequent results were obtained from $11 \mathrm{ml}$ batch cultures. Despite attempts to keep conditions of inoculation and growth rigidly controlled, significant variations in $t_{\mathrm{d}}$ were sometimes observed between experiments regardless of the use of the same n-alkanol at the same concentration. Generally, for a given concentration of a given $\mathrm{n}$-alkanol, a longer $t_{\mathrm{d}}$ was associated with a lower $\mathrm{U} / \mathrm{S}$ ratio. Because of this difficulty, typical data from individual experiments are given, unless the $t_{\mathrm{d}}$ values for the same experimental condition were equivalent $( \pm 3 \mathrm{~min})$.

\section{Glycosyltransferase activity of cells grown in the presence of hexan-1-ol}

As the concentration of hexan-1-ol in the medium was increased to $17.5 \mathrm{mM}$, the U/S ratio of the membrane lipids steadily decreased to a value of $0 \cdot 37$. The most notable changes were in the levels of hexadecanoic acid $(16: 0)$, which increased by $65 \%$, and in octadecenoic $(18: 1)$ and eicosenoic acids $(20: 1)$, which decreased by $47 \%$ and $78 \%$ respectively (Table 3 ).

No GTF activity was detected on the surface of cells grown in the presence of hexan-1-ol (Table 4). However, compared with cells grown in the absence of added alkanol, extracellular GTF activity declined by $84 \%$ in the presence of $7.5 \mathrm{~mm}$-hexan-1-ol. As the concentration of hexan-1-ol was increased above this value, GTF production increased (Table 4). When the hexan-1-ol concentration in the medium was $17.5 \mathrm{mM}$, extracellular GTF activity was $307 \mathrm{mU}$ (mg dry wt) $)^{-1}$, some 31 -fold greater than GTF activity in the presence of $7.5 \mathrm{~mm}$ hexan-1-ol. The $t_{\mathrm{d}}$ of the cells, however, increased by $2 \cdot 5$-fold when the hexan-1-ol concentration was increased from $7.5 \mathrm{~mm}$ to $17.5 \mathrm{mM}$. Although this would allow a greater time for the accumulation of GTF in the culture fluid (Jacques, 1983), the increase in time alone was not sufficient to account for the 31 -fold greater GTF activity.

Both the extracellular and the cell-associated FTF activities of $S$. salivarius decreased with increasing concentrations of hexan-1-ol in the growth medium. The cell-associated activity fell more rapidly than the extracellular activity (Table 4). 


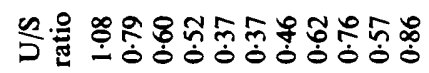
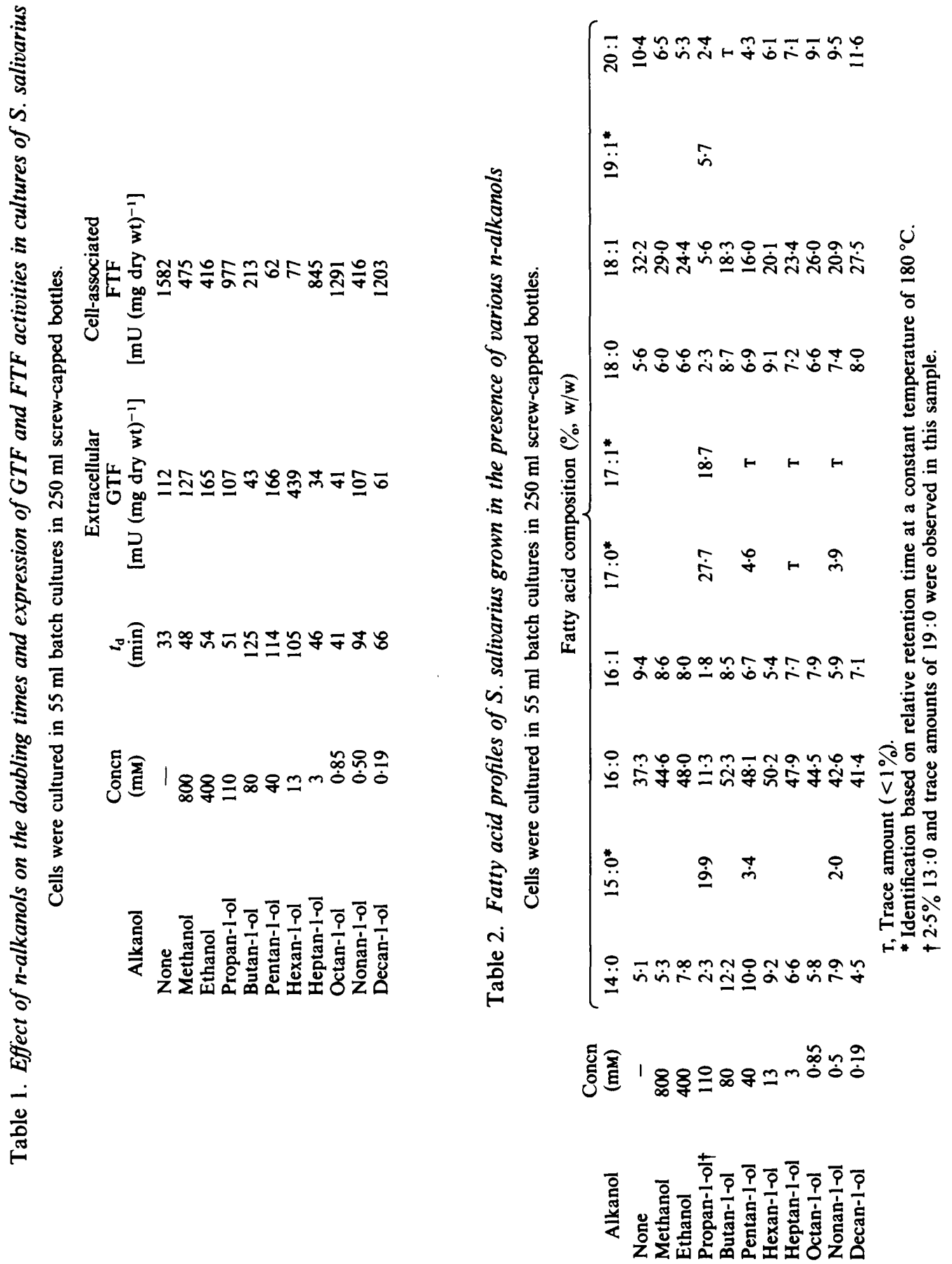
Table 3. Fatty acid profiles of S. salivarius grown in the presence of hexan-1-ol

\begin{tabular}{|c|c|c|c|c|c|c|c|}
\hline \multirow{2}{*}{$\begin{array}{l}\text { Hexan-1-ol } \\
(\mathrm{mM})^{*}\end{array}$} & \multicolumn{6}{|c|}{ Fatty acid composition $(\%, w / w)$} & \multirow{2}{*}{$\begin{array}{c}\mathrm{U} / \mathrm{S} \\
\text { ratio }\end{array}$} \\
\hline & $14: 0$ & $16: 0$ & $16: 1$ & $18: 0$ & $18: 1$ & $20: 1$ & \\
\hline $0.0(8)$ & $2 \cdot 4 \pm 1 \cdot 2$ & $35 \cdot 2 \pm 3 \cdot 0$ & $9.5 \pm 1.9$ & $6.9 \pm 1.7$ & $36 \cdot 5 \pm 2 \cdot 7$ & $9.7 \pm 2.4$ & $1.27 \pm 0.17$ \\
\hline $1 \cdot 0$ & $\overline{1.8}$ & $32 \cdot 7$ & $\overline{7 \cdot 3}$ & $\overline{7} \cdot 7$ & $37 \cdot 5$ & $1 \overline{2} \cdot 9$ & $1 \cdot 37$ \\
\hline $2 \cdot 5$ & $2 \cdot 1$ & 39.9 & 6.9 & 8.0 & $32 \cdot 5$ & $10 \cdot 6$ & 1.00 \\
\hline $5 \cdot 0$ & $2 \cdot 6$ & $43 \cdot 5$ & $8 \cdot 3$ & $7 \cdot 3$ & 28.7 & 9.7 & $0 \cdot 88$ \\
\hline $7 \cdot 5$ & $2 \cdot 8$ & $45 \cdot 2$ & $8 \cdot 6$ & $8 \cdot 5$ & $26 \cdot 5$ & $8 \cdot 4$ & 0.77 \\
\hline $10.0(2)$ & $4 \cdot 6$ & $48 \cdot 4$ & $8 \cdot 2$ & $8 \cdot 2$ & $23 \cdot 3$ & $7 \cdot 5$ & $0 \cdot 64$ \\
\hline $12 \cdot 5(2)$ & $5 \cdot 0$ & $50 \cdot 0$ & 7.6 & $9 \cdot 0$ & 21.8 & 6.7 & 0.57 \\
\hline $15.0(2)$ & $5 \cdot 5$ & 53.9 & 6.6 & $9 \cdot 1$ & $19 \cdot 4$ & $5 \cdot 5$ & 0.46 \\
\hline 17.5 & $5 \cdot 1$ & $58 \cdot 2$ & $5 \cdot 4$ & $10 \cdot 0$ & $19 \cdot 3$ & $2 \cdot 1$ & 0.37 \\
\hline
\end{tabular}

*The numbers in parentheses indicate the number of repeat experiments.

Table 4. GTF and FTF activities of S. salivarius grown in the presence of hexan-1-ol

\begin{tabular}{|c|c|c|c|c|c|}
\hline \multirow{2}{*}{$\begin{array}{l}\text { Hexan-1-ol } \\
\text { (mM) }\end{array}$} & \multirow{2}{*}{$\underset{(\min )}{t_{\mathrm{d}}}$} & \multicolumn{2}{|c|}{ GTF [mU (mg dry wt $\left.)^{-1}\right]$} & \multicolumn{2}{|c|}{ FTF $\left[\mathrm{mU}(\mathrm{mg} \text { dry } w \mathrm{t})^{-1}\right]$} \\
\hline & & Extracellular & Cell-associated & Extracellular & Cell-associated \\
\hline $0 \cdot 0$ & 29 & 61 & 0 & 194 & 1470 \\
\hline $1 \cdot 0$ & 31 & 38 & 0 & 180 & 1377 \\
\hline $2 \cdot 5$ & 30 & 19 & 0 & 158 & 1287 \\
\hline $5 \cdot 0$ & 30 & 16 & 0 & 150 & 950 \\
\hline $7 \cdot 5$ & 32 & 10 & 0 & 125 & 983 \\
\hline $10 \cdot 0$ & 33 & 35 & 0 & 110 & 674 \\
\hline $12 \cdot 5$ & 36 & 91 & 0 & 97 & 377 \\
\hline $15 \cdot 0$ & 38 & 98 & 0 & 92 & 246 \\
\hline $17 \cdot 5$ & 85 & 307 & ND & ND & 150 \\
\hline
\end{tabular}

ND, not determined.

The addition of $17.5 \mathrm{~mm}$-hexan-1-ol to the assay mixture resulted in a minor reduction (4\%) in the measured extracellular GTF activity. Due to dilution of the sample in the assay mixture, this concentration of hexan-1-ol was at least 40 times that present during the assay of the enzyme, if one assumed a $100 \%$ carryover of the $17.5 \mathrm{~mm}$-hexan-1-ol added to the culture medium. In contrast, measured cell-associated FTF activity was reduced by $14 \%$ by the same concentration of hexan-1-ol. The concentation of any n-alkanol transferred into the assay mixture as a contaminant of washed cells was, however, unknown. Similar results were obtained with all other n-alkanols studied.

Similar results to those obtained with hexan-1-ol were observed when cells were cultured with increasing concentrations of pentan-1-ol or heptan-1-ol: cell-associated FTF activity fell more rapidly than extracellular FTF activity (data not shown). Although the effects on extracellular GTF production were not as pronounced as those for growth in the presence of hexan-1-ol, extracellular GTF production increased fivefold in $50 \mathrm{~mm}$-pentan-1-ol compared with the minimum value of $19 \mathrm{mU}(\mathrm{mg} \text { dry } \mathrm{wt})^{-1}$ observed in $20 \mathrm{~mm}$-pentan-1-ol. When cells were grown in the presence of $5 \mathrm{mM}$-heptan-1-ol a twofold increase in extracellular GTF production was observed, compared with the minimum value of $16 \mathrm{mU}(\mathrm{mg} \text { dry wt })^{-1}$ in $2 \mathrm{~mm}$-heptan-1-ol. The average extracellular GTF activity of cells cultured in $11 \mathrm{ml}$ batch cultures in the absence of any added alkanol was $47 \pm 14 \mathrm{mU}(\mathrm{mg} \mathrm{dry} \mathrm{wt})^{-1}(n=10)$. Growth in the presence of either pentan-1-ol or heptan-1-ol resulted in fatty acid changes similar to those observed with hexan-1ol (data not shown). 


\section{Influence of ethanol, propan-1-ol and propanoic acid on cultures of S. salivarius}

The fatty acids of the membrane lipids of $S$. salivarius adapted to the presence of ethanol in the growth medium by increasing the content of hexadecanoic acid $(16: 0)$ essentially at the expense of the octadecenoic acid $(18: 1)$ and eicosenoic acid $(20: 1)$ moieties, a response similar to that seen with other $n$-alkanols (Table 5). As the concentration of ethanol in the medium was increased to $500 \mathrm{mM}$ the $\mathrm{U} / \mathrm{S}$ ratio of the cells decreased to 0.56 whilst the $t_{\mathrm{d}}$ rose steadily to a value of $55 \mathrm{~min}$. Extracellular GTF production fell by $57 \%$ with $300 \mathrm{~mm}$-ethanol, subsequently rising with $450 \mathrm{mM}$-ethanol to a maximum value which was $125 \%$ of that recorded in the absence of added alkanol. No cell-associated GTF activity was observed. Measured cell-associated FTF activity decreased with increasing concentrations of ethanol in the growth medium. With $500 \mathrm{mM}$-ethanol, the value was $68 \%$ less than that of similar cells grown in the absence of added alkanol, where the value was $1655 \pm 151 \mathrm{mU}(\mathrm{mg} \text { dry wt })^{-1}(n=9)$. The extracellular FTF activity remained constant at $250 \pm 37 \mathrm{mU}(\mathrm{mg} \text { dry wt })^{-1}(n=16)$ irrespective of the concentration of ethanol added to the growth medium.

Increasing the concentration of propan-1-ol in the growth medium from 0 to $25 \mathrm{~mm}$ gave rise to increasing proportions of odd-chain-length fatty acids in the membrane lipids. Addition of up to $100 \mathrm{~mm}$-propan-1-ol resulted in little further increase in the odd-chain-length fatty acids (Table 6). However, unlike growth in the presence of any other n-alkanol, the results obtained from separate experiments gave different quantitative patterns for the fatty acid profiles. Major quantitative differences were observed in the levels of pentadecanoic $(15: 0)$, hexadecanoic (16:0), heptadecanoic $(17: 0)$, heptadecenoic $(17: 1)$, and octadecenoic acids $(18: 1)$ between experiments (data not shown).

In contrast to cells grown in the presence of propan-1-ol, the presence of up to $100 \mathrm{~mm}$ propanoic acid in the growth medium caused a small rise in the proportion of odd-chain-length to even-chain-length fatty acids. For comparison, the fatty acid profile of $S$. salivarius grown in the presence of $25 \mathrm{~mm}$-propanoic acid is given in Table 6. Growth of $S$. salivarius in the presence of 25 mM-propan-1-ol (the concentration required for near maximum accumulation of oddchain-length fatty acids) produced a higher proportion of odd-chain-length fatty acids in the membrane lipids than did growth in the presence of 25 mM-propanoic acid.

Extracellular GTF production appeared to be inversely related to the concentration of propan-1-ol present in the growth medium despite an increase in the $t_{\mathrm{d}}$ of the culture from $28 \mathrm{~min}$ to $37 \mathrm{~min}$ as the concentration of propan-1-ol in the medium was increased to $100 \mathrm{mM}$. A $40 \%$ reduction in the extracellular enzyme activity was observed in cells grown in the presence of 100 mM-propan-1-ol. No cell-associated GTF activity was detected in the presence or absence of propan-1-ol.

Extracellular FTF activity remained constant at $235 \pm 32 \mathrm{mU}(\mathrm{mg} \text { dry wt) })^{-1} \quad(n=7)$ throughout the range of concentrations of propan-1-ol added to the growth medium, in a manner similar to that observed for growth in the presence of ethanol. However, unlike the extracellular FTF activity, the cell-associated activity decreased by $38 \%$ as the concentration of propan- 1 -ol in the growth medium was increased to $100 \mathrm{mM}$.

\section{Ethanol as a source of carbon for $S$. salivarius}

The preferred incorporation of odd-chain-length fatty acids into the membrane lipids of $S$. salivarius grown in the presence of propan-1-ol compared with propanoic acid suggested that propan-1-ol could be metabolized via ADH and aldehyde dehydrogenase to propanoyl-CoA, which could subsequently be utilized for catabolic processes including fatty acid biosynthesis. If this were the case, then ethanol should also be metabolized to form acetyl-CoA by the same pathway. This possibility was examined by growing cells in the presence of $400 \mathrm{~mm}$ $\left[{ }^{14} \mathrm{C}\right]$ ethanol. Analysis of the fatty acids of the membrane lipids at the stationary phase of growth indicated that $17.6 \%$ of the carbon of the fatty acids was derived from the ethanol added to the growth medium. 


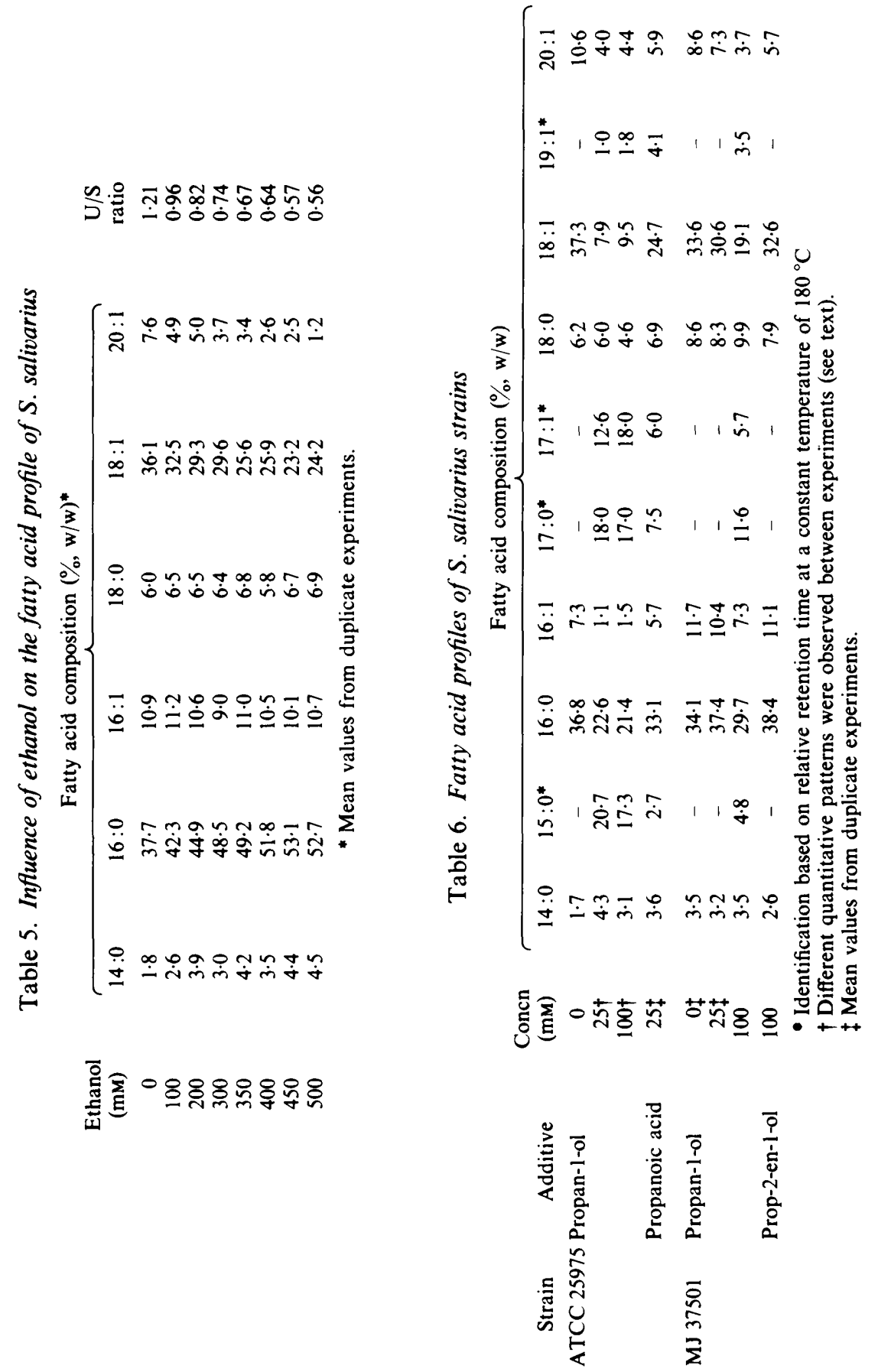

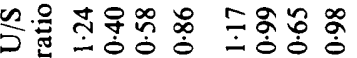




\section{Metabolism of ethanol and propan-1-ol by a constitutive ADH in S. salivarius}

A spontaneous mutant, $S$. salivarius MJ 37501, resistant to 200 mM-prop-2-en-1-ol was isolated. This mutant possessed $3 \%$ of the ethanol dehydrogenase and $1 \%$ of the propan-1-ol dehydrogenase activity of the parent strain, in which specific activities of 4.17 and $3.08 \mu \mathrm{mol}$ $\min ^{-1}$ (mg protein $)^{-1}$ respectively were obtained. The mutant was unable to form odd-chainlength fatty acids when grown in the presence of $25 \mathrm{~mm}$-propan-1-ol, although odd-chain-length fatty acids were detected as the concentration of propan-1-ol in the growth medium was increased above this value. At $100 \mathrm{~mm}$-propan-1-ol, odd-chain-length fatty acids represented $26 \%$ of the total fatty acids, confirming the leaky nature of the $a d h$ mutation in this strain (Table 6). Changes in GTF and FTF expression were similar to those observed by adding ethanol to the growth medium (data not shown).

\section{Influence of prop-2-en-1-ol on S. salivarius $M J 37501$}

The resistance of $S$. salivarius MJ 37501 to prop-2-en-1-ol afforded the opportunity to observe any physiological changes that might occur in cells grown in the presence of an unsaturated linear alkanol. However, growth of the strain in increasing concentrations of prop-2-en-1-ol up to $100 \mathrm{mM}$ failed to significantly influence the $t_{\mathrm{d}}$, cellular or extracellular GTF or FTF expression, or the fatty acid profile of the membrane lipids (Table 6).

\section{DISCUSSION}

When $S$. salivarius was grown in the presence of a series of $n$-alkanols of $C_{1}-C_{10}$ chain length, the concentration of a given n-alkanol required to cause an alteration in the fatty acid composition of the membrane lipids appeared to be inversely related to the chain length, as was found for $E$. coli (Ingram, 1976). Compared with hexan-1-ol for instance, a 40-fold greater concentration of ethanol was required to reduce the $U / S$ ratio to 0.64 - half the value observed in the absence of any added alkanol (Tables 3 and 5). Irrespective of the alkanol added to the growth medium, the membrane fatty acids became more saturated when compared with cells grown in the absence of added alkanol. The changes were in sharp contrast to those reported for $E$. coli $\mathrm{K} 12$, where addition of the short-chain alkanols, methanol to butan-1-ol, caused the degree of saturation to decrease rather than increase (Ingram, 1976).

While incorporation of propanoic acid has been reported to produce odd-chain-length fatty acids in E. coli (Ingram et al., 1977), growth of $S$. salivarius in the presence of 25 mM-propanoic acid elicited a $70 \%$ lesser incorporation of odd-chain-length fatty acids than did growth in the presence of the corresponding n-alkanol at the same concentration. Use of the leaky adh strain, MJ 37501, indicated that high extracellular concentations of propan-1-ol and ethanol could be metabolized via a constitutive ADH activity present in the parent strain. By inference, both ethanol and propan-1-ol crossed the plasma membrane of $S$. salivarius and so, in theory at least, could affect lipid packing at various depths within or on either side of the membrane. For propan-1-ol this transfer was significant at a concentration of $25 \mathrm{~mm}$.

The effects of any set of amphiphilic compounds depend not only on the localization of each member of that set within the membrane but also on the specific depth each member of the set penetrates the bilayer (Brasseur et al., 1985). In the case of $S$. salivarius ATCC 25975, reduced cell-associated FTF activity was observed with increasing concentrations of each n-alkanol studied. In contrast, each member of the set of $n$-alkanols which was examined over a range of concentrations possessed a point at which extracellular GTF production was minimal. Increasing the concentration of the n-alkanol past this point stimulated GTF production. This effect was greatest for hexan-1-ol, since the degree of stimulation of GTF production following the minimum was not as great for the preceding n-alkanol, pentan-1-ol, nor for the following nalkanols heptan-1-ol and octan-1-ol (data not shown). It may be more than coincidental that hexan-1-ol is the n-alkanol which has been reported to have a number of unique physiological effects: for instance it theoretically forms the most stable n-alkanol clusters within a dipalmitoylphosphatidylcholine bilayer (Brasseur et al., 1985), it is the n-alkanol at which a levelling off of inhibition constants $\left(K_{\mathrm{i}}\right)$ for luciferase activity occurs (Franks \& Lieb, 1985) and it is the n-alkanol which causes the greatest changes in the fatty acids and fluidity of $E$. coli 
membranes (Sullivan et al., 1979; Ingram \& Vreeland, 1980). In fact, growth of $S$. salivarius in the presence of $17.5 \mathrm{~mm}$-hexan-1-ol stimulated extracellular GTF production fivefold while suppressing cell-associated FTF expression tenfold. Similar changes of the same order of magnitude for both glycosyltransferase activities occur when cells are grown in the presence of 3-5 mM-octyl $\beta$-D-glucopyranoside (Jacques, 1985). Such a result may imply a similar orientation and perturbation by the surfactant and the $n$-alkanol relative to the protein and lipid components of the membrane.

The high degree of specificity and control of lipid composition in bacterial membranes provides significant circumstantial evidence that lipid composition is critical to membrane function. The present study of the effects of n-alkanols on the fatty acid composition and the mode of expression of the glycosyltransferase enzymes in $S$. salivarius supports such a view.

This work was supported by a Program Grant awarded by the Australian National Health and Medical Research Council. L. W.T. and L. R. were in receipt of Astra Grants for Undergraduate Dental Research and K.K.K. was supported by an undergraduate research scholarship from the Australian Dental Research Fund.

\section{REFERENCES}

BradFORD, M. M. (1976). A rapid and sensitive method for the quantitation of microgram quantities of protein utilizing the principle of protein-dye binding. Analytical Biochemistry 72, 248-254.

Brasseur, R., Chatelain, P., Goormaghtigh, E. AND RUYSSCHAERT, J.-M. (1985). A semi-empirical conformational analysis of the interactions of $n$-alkanols with dipalmitoylphosphatidylcholine. Biochimica et biophysica acta 814, 227-236.

DOMBEK, K. M. \& INGRAM, L. O. (1984). Effects of ethanol on the Escherichia coli plasma membrane. Journal of Bacteriology 157, 233-239.

Franks, N. P. \& LiEB, W. R. (1985). Mapping of general anaesthetic target sites provides a molecular basis for cutoff effects. Nature, London 316, 349-351.

Fishman, Y., Rottem, S. \& CiTRI, N. (1980). Preferential suppression of normal exoenzyme formation by membrane-modifying agents. Journal of Bacteriology 141, 1435-1438.

Herrero, A. A., Gomez, R. F. \& Roberts, M. F (1982). Ethanol-induced changes in the membrane lipid composition of Clostridium thermocellum. Biochimica et biophysica acta 693, 195-204.

INGRAM, L. O. (1976). Adaptation of membrane lipids to alcohols. Journal of Bacteriology 125, 670-678.

INGRAM, L. O. (1982). Regulation of fatty acid composition in Escherichia coli: a proposed common mechanism for changes induced by ethanol, chaotropic agents and a reduction of growth temperature. Journal of Bacteriology 149, 166-172.

INGRAM, L. O. \& VREELAND, N. S. (1980). Differential effects of ethanol and hexanol on the Escherichia coli cell envelope. Journal of Bacteriology 144, 481-488.

Ingram, L. O., Chevalier, L. S., Gabbay, E. J., Ley, K. D. \& WINTERS, K. (1977). Propionate-induced synthesis of odd-chain-length fatty acids by Escherichia coli. Journal of Bacteriology 131, 1023-1025.

JACQUES, N. A. (1983). Membrane perturbation by cerulenin modulates glucosyltransferase secretion and acetate uptake by Streptococcus salivarius. Journal of General Microbiology 129, 3293-3302.

JACQUES, N. A. (1985). Inhibition of the expression of cell-associated fructosyltransferase in Streptococcus salivarius by octyl $\beta$-D-glucopyranoside. Journal of General Microbiology 131, 3243-3250.
Jacques, N. A., Jacques, V. L., Wolf, A. C. \& Wittenberger, C. L. (1985). Does an increase in membrane unsaturated fatty acids account for Tween 80 stimulation of glucosyltransferase secretion by Streptococcus salivarius? Journal of General Microbiology 131, 67-72.

MarkeVics, L. J. \& JacQues, N. A. (1985). Enhanced secretion of glucosyltransferase by changes in potassium ion concentrations is accompanied by an altered pattern of membrane fatty acids in Streptococcus salivarius. Journal of Bacteriology 161, 989994.

MARR, A. G. \& IngRaham, J. L. (1962). Effect of temperature on the composition of fatty acids in Escherichia coli. Journal of Bacteriology 84, 12601267.

RACKER, E. (1955). Alcohol dehydrogenase from baker's yeast. Methods in Enzymology 1, 500-503.

RANDO, R. R. (1974). Allyl alcohol-induced irreversible inhibition of yeast alcohol dehydrogenase. Biochemical Pharmacology 23, 2328-2331.

Rigomier, D., BoHIN, J.-P. \& LUBochinsKy, B. (1980). Effects of ethanol and methanol on lipid metabolism in Bacillus subtilis. Journal of General Microbiology 121, 139-149.

SeEman, P. (1972). The membrane actions of anaesthetics and tranquilizers. Pharmacological Reviews 24, 583-655.

Shimamura, A., Tsumori, H. \& Mukasa, H. (1983). Three kinds of extracellular glucosyltransferases from Streptococcus mutans 6715 (serotype g). FEBS Letters 157, 79-83.

Sullivan, K. H., Hegeman, G. D. \& Cordes, E. H. (1979). Alteration of the fatty acid composition of Escherichia coli by growth in the presence of normal alcohols. Journal of Bacteriology 138, 133-138.

UMESAKI, Y., KaWAI, Y. \& MUTAI, M. (1977). Effect of Tween 80 on glucosyltransferase production in Streptococcus mutans. Applied and Environmental Microbiology 34, 115-119.

Yokogawa, K., Kawata, S., Takemura, T. \& Yoshimura, Y. (1975). Purification and properties of lytic enzymes from Streptomyces globisporus 1829 . Agricultural and Biological Chemistry 39, 1533-1543. 